Alessandro Delfanti
University of Toronto

\title{
Distributed Biotechnology
}

Draft version 1, March 2016

\section{Introduction}

In the last decade a new ecosystem of do-it-yourself biology groups, biotech start-ups and community labs has emerged in both Europe and North America, as well as in South East Asia. This interconnected ecosystem of what I call "distributed biotechnology" is part of broader transformations of the relation between technological and scientific innovation and society. Indeed it mirrors the emergence of similar trends in other forms of sociotechnical innovation towards distributed models, such as those embodied by the maker movement or the growth of do-it-yourself approaches in several areas of social and technological innovation. It differs from traditional forms of citizen science as it draws elements from hacker cultures and has adopted molecular biology as its main scientific framework. Distributed biotechnology includes phenomena such as amateur do-it-yourself biology, as well as an emergent set of companies and start-ups that provide laboratory equipment and digital platforms designed to foster citizen contribution to biotechnology research. Distributed means that actors do not depend from centralized hubs and tend toward forms of peer-to-peer collaboration; threshold to access are relatively low; and connections between different hubs and actors are created and maintained through the open circulation of people, materials, and information. This interconnected ecosystem is at times characterized by a perceived and sought-after independency from, if not opposition to, incumbent institutional actors such as corporate and university labs.

Phenomena such as citizen science have long been used as examples of the permeable boundaries of scientific knowledge production, especially within Science and Technology Studies. Yet it is only since the first draft of the human genome was sequenced and published in 2000 that the diffusion of equipment for DNA extraction, sequencing, recombination, and eventually synthesis has been made available to a broader public. Also, following similar phenomena in the digital sphere, distributed biotechnology emerged not only out of technological change, but also from political and cultural transformations. It is in fact based on the availability of relatively cheap and accessible equipment such as PCR machines, centrifuges, vectors or microscopes; the emergence of a series of community laboratories 
explicitly directed to amateurs; the broad availability of shared information such as biotech protocols or genetic sequences through open access databases; and finally, the influence of digitally-mediated participatory cultures within science. While the actors I refer to as part of contemporary distributed biotechnology are arguably quite diverse and heterogeneous, I use the metaphor of an ecosystem as a sphere in which different organisms coexist, exchange resources and information, and thus coevolve. Distributed biotechnology aims at broadening the reach of life science research beyond the limits of traditional institutional laboratories. In this chapter I conflate arguably heterogeneous phenomena as part of an emerging ecosystem of distributed biotechnology, and thus include start-up networks, community and amateur labs, and biohackerspaces.

The series of changes that have opened up new spaces for biotechnological research to be conducted outside of the boundaries of scientific institutions and corporate laboratories have been described through metaphors such as "craft," which highlighted the scalability of biotech towards small-scale interventions in opposition to professionalization of mainstream biotech (Roosth 2011). Definitions such as "kitchen" or "garage" biology touch upon the same trope while helping understand how these forms of amateur biology are gendered (Jen 2015). Other scholars have referred explicitly to DIY biology as a step towards an increased democratization of biotechnology, for example through processes of "domestication" or "demystification" that question the separation between expert and amateur (Frow 2015, Meyer 2013, see Wolinsky 2009). Scholarship analyzing the rise of phenomena such as do-it-yourself biology since the mid2000s has also focused on the relation between distributed biology and hacking, thus adopting the term biohacking as an umbrella term to refer to different forms of distributed intervention in the life sciences (Davies 2015, Delfanti 2013, Kelty 2010). This choice reflects the selfascribed genealogy that many DIY biologists or entrepreneurs construct. At the same time the use of the term biohacking has allowed scholars to highlight the ambivalent relation that DIY biologists have with scientific and biomedical research institutions and corporations. This mirrors similar concerns about the role of contemporary open science as a site where new forms of appropriation of the value produced by scientific research are experimented with and established (Birch 2012, Tyfield 2013).

Following a similar critical approach, in this chapter I present the genealogies that underpin new forms of distributed biotech, and explore a set of characteristics of its political economy. Distributed biotech has been imagined and practiced in radical artistic milieus that aim at opening up the process of DNA recombination in order to critique the dominance of multinational corporations in the biotechnology sector. In a parallel genealogy, distributed 
biotechnology has also been constructed as a form of personal technology by actors from the industrial and academic world. This has created a wave of both community labs and new companies that attempt at creating a new market for biotech equipment and services. The construction of "openness" as a set of organizational and political characteristics, such as open source information exchange, open citizen participation, and open markets, is a crucial foundation of distributed biotech. This combination aims at re-moralizing biotechnology by constructing it as consumer-friendly, non-proprietary and participatory. By creating new entrepreneurial subjects and exploiting outsourced labor, distributed biotech may contribute to broader phenomena of market and labor deregulation. Finally, it is subject to processes of cooption and institutionalization that integrate its technologies and practices within new contexts, while at the same time diluting their intended disruptive potential. Distributed biology has emerged out of different socio-political context and ways of understanding living matter. As it matures, it is increasingly participating in a reconfiguration of the relation between research and society.

\section{Critique of the biotech industry}

Since the early 2000s the possibility of reappropriating biotech through distributed and participatory research has been explicitly presented as a critique of the political economy of corporate biotechnology. Artists aimed at using biotech tools and practices to criticize the biotechnological industry for its lack of transparency, reliance on intellectual property rights, and environmental impact. Groups related to hacker cultures struggled to create permeable spaces where political and artistic explorations of biology could express confrontational practices that addressed the power of the industrial and academic sectors. Through definitions such as as "outlaw biology," scholars have recognized this willingness to perform biotech outside of the realm of state regulation, while at the same time stressing its limited scope and nuanced genealogy (Kelty 2010).

Among other artists and collectives using so-called "bioart" as a form of political intervention, the United States art collective Critical Art Ensemble (CAE) stands out as the most influential and recognized case. In the early 2000s, CAE designed several citizen science performances that were explicitly framed as oppositional to the biotechnological industry. CAE called for the emergence of a "contestational biology" as a tool to challenge the structures of power within market relationships and the role of biotechnology in today's capitalist societies--in their words, “molecular capitalism" (2002). In its Free Range Grain public performance, for example, the art 
collective allowed the public to test foods through basic molecular biology techniques. Distributing the means for searching for genetically modified crops contamination was meant to counter the disempowerment produced by the role of multinational corporations in agrobiotech. In its proposal for new forms of "fuzzy biological sabotage," CAE imagined that genetic hacking could provide activist groups with biological tools to counter the expansion of harmful GM organisms.

CAE explicitly framed its activities as oppositional to the biotechnological industry, theorizing biohacking as a tool to challenge the structures of power within market relationships and the role of biotechnology in today's capitalist societies. Although similar politicized activities seem to be confined to the art sphere, this trend continues nowadays, especially in Europe and Asia. Art collectives such as the group Hackteria, based in Switzerland, routinely organize workshops that aim at reappropriating biotech, for example by teaching how to build a DIY gel electrophoresis chamber in an IKEA tupperware. These actors tend to represent the political economy of biotech as a site of conflict and contestation, while its reappropriation through DIY approaches is constructed as a form of tactical intervention (Magrini 2014). As ethical concerns about the impact of biotechnology on the environment or human nature tend to become relatively marginal, at least in these spheres, political activism expressed through distributed biotechnology keeps on shifting towards a concern about the structure of ownership and the hierarchies that characterize the biotech industry.

The influence of hacker cultures led to proposals for a radical reappropriation of biotechnology that were driven by an urge to criticize the monopoly of institutional biotech within a different political framework. Written in the US in 2010, the Biopunk Manifesto synthesizes some common critiques to this monopoly while introducing the idea that freedom of research should be equaled to freedom of speech: "we reject the popular perception that science is only done in million-dollar university, government, or corporate labs; we assert that the right of freedom of inquiry, to do research and pursue understanding under one's own direction, is as fundamental a right as that of free speech or freedom of religion" (Patterson 2010). This and other documents point out a problem in the distribution of power in biology and have been inspirational for subsequent waves of biohackers.

The role of these attempts at using distributed biotech to explicitly criticize the political economy of contemporary biotechnology should not be overrated. Based on ethnographic research, scholars have balanced descriptions of a politicized and "outlaw" biotech, highlighting areas of political ambivalence (Delfanti 2013). For example, through the construction of the 
need for biosafety regulation, distributed biotechnology has been prompted to engage in negotiations with state actors. This is the case of the DIYbio network in the United States and the relation it built with the Federal Bureau of Investigation in the early 2010s in order to construct do-it-yourself activities as legitimate and safe. This created frictions with some European groups (Tocchetti and Aguiton 2015). Also, in most cases distributed technology seems to emerge out of a direct relation with, rather than in opposition to, incumbent institutional actors.

\section{Biotechnology becomes personal}

A parallel yet different genealogy of contemporary distributed biotechnology is rooted in attempts at transforming molecular biology in a personal technology while resisting its politicization. In the mid-2000s a new wave of efforts at imagining and practicing forms of distributed biotechnology emerged in academic departments and then spread to both amateur communities and entrepreneurial milieus. This genealogy is based on the construction of new mechanisms to intervene in living matter, as well as in a broadened inclusion of new constituencies and the emergence of an infrastructure of distributed biotechnology laboratories, tools, and digital platforms.

These efforts emerged out of attempts dating back to the early 2000 s at constructing biological matter as composed of standardized, interchangeable parts that could be tinkered with. These early processes came to define and construct what we now call synthetic biology. The Registry of Standardized Biological Parts is a database of BioBricks, genetic parts that can be assembled into full DNA sequences. Put forward by US geneticists such as Tom Knight and Drew Endy, this project was coupled with platforms for open information exchange such as the OpenWetWare wiki, an online service for sharing information about synthetic biology protocols and materials. Similar phenomena rely on an approach to DNA and living matter not just as information, but also as pliable material which, like software, can be made hackable and shareable (Calvert 2010). This is related to a broader shift of the scientific enterprise towards computation as a core tool as well as cultural framework for research. These forms of synthetic biology are also the result of a willingness to challenge the idea that biotech must based on the strict enforcement of exclusive intellectual property rights. At the same time they fostered the opening of synthetic biology to new publics (Hilgartner 2012, TBA 2016). The iGEM competition (International Genetically Engineered Machine), hosted by MIT since 2003/2004, is an international competition in which teams of students from universities or countries use 
BioBricks in order to produce synthetic organisms. The aim of iGEM is to produce "open and transparent tools" for the development of biotech. Inspired by free, libre and open source software (FLOSS) and yet geared towards molecules and cells rather than bits, such sites were foundational in the birth of contemporary synthetic biology.

Later on, the idea of expanding access to synthetic biology was directed towards broader publics, such as those identified in a 2005 Wired article by the US biotechnologist Robert Carlson ("Splice It Yourself", 2005). Carlson called for new forms of distributed biotechnology that he referred to as "garage biotech" with a reference to the Silicon Valley garage, depicted in many accounts of the history of computers as a core site of disruptive innovation. This and other conceptualizations of biotech as accessible from non-institutional spaces such as garages or backyards were based upon the idea that biology had witnessed the emergence of the same premises that allow for the existence of online peer-to-peer production: the availability of affordable hardware in form of equipment and machinery; an online infrastructure for sharing protocols and data; collaborative software services; broad availability of data and information that are easily accessible and in the public domain; copyleft licenses that allow content reuse, modification and redistribution; and a culture of participation (Delfanti 2013, Meyer 2012). Under this banner, DIYbio (do-it-yourself biology) was born, preceded by attempts at creating similar US projects through projects such as the 2007 Open Biohacking Kit or the website biopunk.org (TBA 2016).

DIYbio is a loose network of amateur biologists launched in Boston in 2008 by Jason Bobe and MacKenzie Cowell. The two were already actively involved in projects such as the iGEM competition and the Personal Genome Project, and with the launch of DIYbio they aimed at fulfilling the idea of a distributed, citizen biology led by non-experts, a "science without scientists" (Bobe 2008). Initially organized around a local group and a website, DIYbio has come to represent the most significant early example of a distributed biotechnology community, and has had a global influence on similar groups. DIYbio was constructed as a site for experimentation where biology was to be made accessible to anyone, regardless of formal education, technical skills or institutional affiliation. Under the umbrella of DIYbio, distributed biotech has indeed attracted new publics to biotechnology and other forms of life science research. Following the launch of DIYbio in 2008, a series of spaces for the development of distributed biotech started emerging in urban environments. Predominantly white and male, at least initially, amateur biologists have formed groups in many cities in North America and Western Europe, with a recent expansion in Asia and South America (Kera 2012, Meyer 2013). These groups tend to include individuals with a series of different backgrounds. In many cases, 
a core constituency is composed by biology students and computer programmers, while other individuals are interested in art and design, or have a different scientific background. In a significant number of cases, DIYbio participants seem to be students or biologists that are frustrated with the hierarchies and lack of freedom they experience in the institutional laboratories they work for (Delfanti 2013, Delgado 2013, Grushkin et al. 2013, Landrain et al. 2013). Since the beginning, DIYbio participants have constructed this form of distributed biotechnology as independent from, although not opposed to, scientific institutions.

While recurrent early rhetorics would depict distributed biotech or biohacking as happening in kitchens, garages or backyards, the spaces where early non-institutional laboratories were set up were rather community spaces or hackerspaces. After the launch of DIYbio in 2008, DIY labs have been established in cities in North America and Europe, such as GenSpace in New York (2010), Biologigaragen in Copenhagen (2010), Biocurious in Sunnyvale, California (2011), La Paillasse in Paris (2011) or Counter Culture Labs in Oakland (2014) (Delfanti 2013, Meyer 2013). In many cases, such as Seattle, Los Angeles, Copenhagen or Toronto, DIY biolabs have been set up as "wet" corners within existing hackerspaces or makerspaces. Although characterized by different local and political cultures, the shared goal of these and other biohackerspaces is to make available community-run labs where non-professionals can have access to basic equipment for biological research, such as glassware, centrifuges, polymerase chain reaction machines, or gel electrophoresis. While in some cases early labs would be equipped with scrap or stolen equipment, DIYbio participants and an emerging network of start-up companies would soon start designing and producing open source lab equipment for recombinant DNA technologies, such as the early flagship projects Open Gel Box or OpenPCR. This DIYbio open source technical equipment is designed to be directly transformable by individual users and groups, as well as based on shared protocols (Kera 2012). Further evolutions aimed at blackboxing DIYbio machines while making them affordable and consumerfriendly. This is the case of portable, laptop-sized biotech labs commercialized in the mid-2010s: Bento Lab includes a PCR machine, a centrifuge and a gel electrophoresis unit and presents itself as part of "a mission to make bio available to all;" The Amino is a unit for cell cultures that runs pre-determined "apps," that is, kits for synthetic biology production. Since early attempts at producing open source tools, the ecosystem of distributed biotech has thus been enriched by the launch of start-up companies and accelerators that tap into an emerging market for personal biotech products (Palmer and Jewett 2014).

Indeed although at first it emerged out of an academic context, the idea that DIYbio could embody the dream of a personal biotechnology is the product of a more complex genealogy. A 
relation with the maker movement has been pointed out as a major factor in its emergence. In the US, this has taken the form of a direct relation, as made explicit in the relation between MAKE Magazine and DIYbio. MAKE Magazine, arguably one of the flag-bearer publications of the US maker movement, has been instrumental in constructing biology as a personal technology that makes biotech socially meaningful by putting it in the hands of new publics (Tocchetti 2012). Tocchetti builds upon works that have described the influence of US countercultures on the 1970s emerging computer industry, when it was first imagined that computers could be personal technologies fit for mass commercialization rather than technologies targeted at bureaucratic institutions such as the military or universities (Turner 2006). The inclusion of DIY biology within a broader maker culture has allowed biohacking to become a site in which biotechnological interventions on life can be based on small-scale technology and bestowed upon the hands of a new entrepreneurial subject, the maker (Tocchetti 2012). This entrepreneurial self, embodied by a set of start-up companies working within the distributed biotech ecosystem, contributes to claims that a personal biotech should be constructed as complementary rather than in opposition to corporate and academic incumbents. In this renewed context, the political economy of corporate biotech is to be challenged only insofar as it is tackled as a problem of industry concentration, rather than an issue of commercialization.

\section{Openness as a new moral ground}

Spilling from free and open source software onto areas as heterogeneous as technological development, journalism, and politics, "openness" has come to represent a crucial driver of legitimization of contemporary societies (Tkacz 2015). In scientific research, the emergence of digitalization has implied not only an epistemic change but also a rewriting of how morality is constructed through openness. The idea that scientific research is based on a moral economy was introduced to conceptualize science as a system of exchange based upon normative models and composed by a set of social values that underlie and govern exchange within a scientific community, in particular in relation to property (who owns what), privacy (who can know what) and priority (who gets credit for what) (Daston 1995). In the area of distributed biotechnology, it has been proposed that the exchange of genetic parts in open source synthetic biology is the evolution of earlier moral economies that underpinned the 20th century exchange of basic tools of research such as model organisms, for example arabidopsis or drosophila (Kelty 2012). Yet while this model refers to internal incentives and cultures, the moral economy of openness that 
sustains distributed biotech seems to represent a further step towards the construction of forms of public legitimization.

Openness, in other words, has become a crucial test of public morality (Boltanski and Thevenot 2006). This has allowed the rise of distributed biotechnology, especially in the case of synthetic biology, to become part of a project of re-moralization of the biotech industry in the wake of political contestations over research privatization and corporate monopolies in both agrobiotech and medical biotech (Tyfield 2013). Indeed the exchange of information, tools and materials that underpin distributed biotechnology is based, albeit in different forms, on three complementary dimensions of openness: open source information, open participation, and open markets. The first two forms of openness have emerged from the genealogies of distributed biotech in politicized art circles as well as in mainstream biology. The idea that a new kind of biotechnology could be modeled after free and open source software means that it could be distributed not only by adopting technical open source arrangements such as open licenses, but also by including new non-expert publics. Thus on the one hand openness refers to the use of alternative forms of property and control, adapted from the software world, that help make information and processes available to distributed publics. On the other, these new and broadened publics are created through a political form of openness that grants access to distributed biotech while making power open to scrutiny and transformation (Kelty 2010).

Finally, a further form of openness refers to the creation of open markets for consumer-friendly products that can be developed and commercialized by new economic actors such as start-up companies or community-based actors that compete against the market concentration represented by pharmaceutical and agrobiotech corporations. The interplay of these different dimensions of openness has come to represent the technical and moral infrastructure that underpins distributed biotech. Openness is thus a multifaceted element rooted in technical, legal and moral decisions (TBA 2016). Through its openness, distributed biotech is constructed as non-proprietary, participatory, transparent, user- and consumer-friendly, as well as opposed to monopolies and market concentrations, while fostering new forms of commodification (Deibel 2014). This makes distributed biotech a site where tensions towards a collective and participatory biology coexist with forms of commercialization within a common framework of public morality. While several authors have denounced the ambivalence of this project (Birch 2012, Delfanti 2013, TBA 2016, Tyfield 2013), the incorporation of this multi-faceted form of openness into the moral economy of distributed biotechnology seems to leave the field relatively open to political change. 


\section{Institutionalization and commercialization}

While recurrent rhetorics construct distributed biotech as autonomous and independent from, if not opposed to, incumbent corporate and academic institutions, processes of increasing institutionalization are at play. Contra accounts that present new forms of distributed biotech such as DIY biology or citizen science as a reappropriation of life science research, some authors have stated that the trajectory of distributed biotech is one of further integration within the industrial, academic, and education sectors. Indeed distributed biotechnology is strictly intertwined with academic and corporate laboratories, as DIYbio communities rely on them for skills, equipment, and tools. According to surveys and ethnographic accounts alike, a sensible percentage of DIYbio practitioners also work in an academic, corporate or government lab (Grushkin et al 2013, Seyfried et al. 2014). These members constitute a crucial core group that provides skills and resources and leads the development of biohackerspaces, community labs and start-ups. Also, academic institutions appear to have a growing interest in funding do-ityourself biology or establishing partnerships with it, following a trend of inclusion that is increasingly common among other forms of citizen science (Grushkin et al. 2013, Landrain et al. 2013). Yet while the origins of distributed biotech in academic and entrepreneurial circles may suggest that distributed biotech has always been highly intertwined with mainstream biology, processes of further integration seem to be at play, as distributed biotech keeps on being technologically dependent from its mainstream counterpart (Delgado 2013).

Processes of institutionalization typically studied in social movements have been observed in groups that use alternative technological innovation as a tool for social change. These alternative technologies and processes are often developed with the help of entrepreneurial coalitions and are eventually incorporated by the industry, which then transforms and adapts them according to its needs (Hess 2005). One standard such story is the rise of open source software as a market-friendly evolution of free software. Institutions tend to partially adopt alternative technologies and socio-technical practices while at the same time altering and neutralizing them. These dynamics of co-option are at play for hacking, which evolves in symbiosis with industry partners and experiences cycles of co-option and institutionalization (Delfanti and Soderberg 2016). Organizational practices geared towards the fostering of distributed innovation and derived from hacker cultures, such as hackatons, are subject to uptake by institutional actors, as they can be used to produce and celebrate a neoliberal entrepreneurial subjectivity that resonates with Silicon Valley cultures (Irani 2015). 
The emergence of an array of start-up companies inspired by biohacking, especially in the US, is a sign of the influence of distributed biotech in entrepreneurial milieus and its ongoing institutional integration. This reflects market-based shifts as science and health are increasingly mediated by private corporations through processes of individual consumption. In fact, distributed biotech builds upon phenomena such as direct-to-consumer genetic testing and personalized genomics, while providing a cultural and technological infrastructure for synthetic biology research. Early examples of such transformation towards commercialization are companies that design web-based platforms for distributed synthetic biology which invite wide publics to participate in drug development. Accelerators such as IndieBio, based in both the US and EU, fund "independent" biotech start-ups and help them position on the market. The appearance of corporate distributed biotech fosters the further mobilization of new publics as active contributors to biotech research, but at the same time guarantees that these same publics can participate in the commercialization of products deriving from their contributions. Analyzing distributed drug development, scholars have stressed that such publics may represent deregulated outsourced laborers and at the same time potential consumers (Cooper and Waldby 2014, Lupton 2014). On the other hand, the emergence of a distributed biotech start-up ecosystem is also part of an ongoing process of financial risk outsourcing in which pharmaceutical and biotech corporations harness value created by high-risk new companies in the form of intellectual property or services. This also signals that distributed biotechnology might drop technical openness in favour of traditional intellectual property rights when adopted by market-based actors (Delfanti 2013).

Finally, some of the practices, equipment, and aesthetics stemming from DIYbio and other forms of biohacking are adopted and repurposed by educational institutions such as universities and museums. Examples of the adoption of distributed biotech as a form of public communication includes a number citizen laboratories opened by European universities, museum exhibitions on DIYbio, and collaborations between DIYbio community labs and schools to provide biotech-related student activities. Portable labs such as Bento or The Amino are commercialized as suitable for schools, while community labs such as New York's GenSpace collaborate with science teachers within the city in order to provide scientific education programs. Distributed biotechnology's emphasis on enabling citizens to directly carry out scientific research through hands-on approaches resonates with the educational goal of showing the processes that underpin biotech rathern than its final results (Davies et al. 2015). Similarly, European groups have been involved in EU-funded research projects aiming at experimenting new forms of citizen participation under the umbrella of the European bioeconomy. Within these new frameworks, distributed biotech's goal of creating new spaces of access for wider 
publics seems to dilute the emphasis on the possibility of an independent if not oppositional biotech, and has become part of a more standard narrative about the need for an increased consensus around biotech.

\section{Conclusions}

Although by its scale it could be considered as marginal if compared to major actors such as agrobiotech corporations or academic institutions, distributed biotechnology has been central to recent political transformations of the relation between biology and society. Distributed biotech is constituted of an ecosystem populated by different actors that exchange people, material and information. Do-it-yourself biology groups, biohackerspaces, start-ups, incubators, as well as education and academic institutions all concur to shape it. Its structure is the product of a number of genealogies that albeit culturally and socially diverse share a dissatisfaction with the political economy or mainstream biotechnology. Also, distributed biotech constructs its activities through a complex entanglement of different forms of technical, cultural, and moral openness that are derived from software cultures. Yet while actors in distributed biotechnology communities or companies tend to construct their activities as separated from mainstream biomedical research, processes of dependence and increased institutionalization are at play.

Practitioners, pundits, and scholars alike have explicitly linked the trajectory of DIY and distributed biotechnology to that of personal computers in the 1970s. Under the influence of post-1968 countercultures hackers first imagined that the computer could become personal: a community-based tool for liberation at first, and an individual tool for mediated communication later. This led to the commercialization of computers as personal technologies designed for mass consumption, breaking a monopoly held by corporations which saw computers as tools for experts and institutions. This story is often told as an edifying narrative of democratization and economic success. And yet a more nuanced comparison between personal computing and personal biotech could help highlight the contestations, ambivalences and tensions that characterize the rise of new forms of biotechnology and their relation with broader societal and political issues. 


\section{References}

Birch, K. 2012 “An open biotechnology revolution?” Science as Culture 21(3): 415-419.

Bobe, J., 2008 "Science without scientists"

http://diybio.org/blog/science-without-scientists, accessed February 2016

Boltanski, L. and Thévenot, L. 2006 On Justification: Economies of worth. Princeton: Princeton University Press.

Calvert, J. 2010 "Synthetic biology: constructing nature?" The Sociological Review 58.s1: 95-112.

Carlson, R., 2005 "Splice it yourself”, Wired.

http://www.wired.com/wired/archive/13.05/view.html?pg=2, accessed January 2016

Cooper, M. and Waldby, C. 2014 Clinical Labor: Tissue Donors and Research Subjects in the Global Bioeconomy. Duke University Press, 2014.

Critical Art Ensemble, 2002 The Molecular Invasion. New York: Autonomedia.

Daston, L. 1995 “The moral economy of science" Osiris 10: 2-24.

Davies, Sarah R., et al. 2015 "Co-Curation as Hacking: Biohackers in Copenhagen's Medical Museion" Curator: The Museum Journal 58(1): 117-131.

Deibel, E. 2014 "Open Genetic Code: on open source in the life sciences" Life Sciences, Society and Policy 10.1: 1-23.

Delfanti, A. 2013 Biohackers. The Politics of Open Science. London: Pluto Press

Delfanti, A. and Soderberg, J. 2016 "Repurposing the hacker. Three temporalities of recuperation" (full reference TBA).

Delgado, A. 2013. “DIYbio: Making Things and Making Futures.” Futures 48: 65-73.

Frow, E. 2015 "Rhetorics and practices of democratization in synthetic biology." In Wienroth, M. and Rodrigues, E., Knowing New Biotechnologies: Social Aspects of Technological Convergence. New York: Routledge: 174-187. 
Grushkin, D., Kuiken, T., and Millet, P. 2013 "Seven myths and realities about do-it-yourself biology" Woodrow Wilson International Center for Scholars, Washington, DC.

Hess, D. 2005 "Technology-and product-oriented movements: Approximating social movement studies and science and technology studies”, Science, Technology \& Human Values 30 (4): pp. 515535.

Hilgartner, S. 2012 "Novel constitutions? New regimes of openness in synthetic biology" BioSocieties 7.2: $188-207$.

Irani, L. 2015 "Hackathons and the Making of Entrepreneurial Citizenship" Science, Technology \& Human Values 40.5: 799-824.

Jen, C. 2015 "Do-it-yourself biology, garage biology, and kitchen science." Wienroth, M. and Rodrigues, E., Knowing New Biotechnologies: Social Aspects of Technological Convergence. New York: Routledge: 125-141.

Kelty, C., 2010 "Outlaw, hackers, victorian amateurs: diagnosing public participation in the life sciences today” Journal of Science Communication 09 (01).

Kelty, C. 2012 "This is not an Article: Model Organism Newsletters and the Question of 'Open Science'." BioSocieties 7.2: 140-168.

Kera, D. 2012 "Hackerspaces and DIYbio in Asia: connecting science and community with open data, kits and protocols" Journal of Peer Production 2: 1-8.

Landrain, T., Meyer, M., Perez, A.M., and Sussan, R. 2013 "Do-it-yourself Biology: Challenges and Promises for an Open Science and Technology Movement." Systems and Synthetic Biology 7.3: 115126.

Lupton, D. 2014 "Critical perspectives on digital health technologies" Sociology Compass 8.12: 13441359.

Magrini, B. 2014 "Hackteria: An Example of Neomodern Activism." Leonardo Electronic Almanac 20.1: 58-71. 
Meyer, M., 2012 "Build your own lab: Do-It-Yourself Biology and the Rise of Citizen BiotechEconomies" Journal of Peer Production 2.

Meyer, M. 2013 "Domesticating and democratizing science: a geography of do-it-yourself biology" Journal of Material Culture 18.2: 117-134.

Palmer, M. and Jewett M. 2014 "Enabling a Next Generation of Synthetic Biology Community Organization and Leadership" ACS synthetic biology 3.3: 117-120.

Patterson, M., 2010 A Biopunk Manifesto.

http://maradydd.livejournal.com/496085.html, accessed February 2016.

Roosth, S. 2011 Crafting Life; A Sensory Ethnography of Fabricated Biologies. Ph.D dissertation, Cambridge: Massachusetts Institute of Technology.

Seyfried, G, Pei, L., and Schmidt, M. 2014 "European do-it-yourself (DIY) biology: Beyond the hope, hype and horror" Bioessays 36.6: 548-551.

TBA 2016 (full reference TBA)

Tkacz, N. 2015 Wikipedia and the Politics of Openness. Chicago: University of Chicago Press.

Tocchetti, S., 2012 "DIYbiologists as 'makers' of personal biologies: How MAKE Magazine and Maker faires contribute in constituting biology as a personal technology" Journal of Peer Production 1 (2).

Tocchetti, S., and Aguiton, S. 2015 "Is an FBI Agent a DIY Biologist Like Any Other? A Cultural Analysis of a Biosecurity Risk.” Science, Technology \& Human Values 40.5: 825-853.

Turner, F. 2006 From Counterculture to Cyberculture: Stewart Brand, the Whole Earth Network, and the Rise of Digital Utopianism. Chicago: University Of Chicago Press.

Tyfield, D. 2013 “Transition to Science 2.0: 'Remoralizing' the Economy of Science" Spontaneous Generations: A Journal for the History and Philosophy of Science 7.1: 29-48.

Wolinsky, H. 2009 “Kitchen biology” EMBO Reports 10.7 (2009): 683-685. 